\title{
Assessment and molecular characterization of Bacillus cereus isolated from edible fungi in China
}

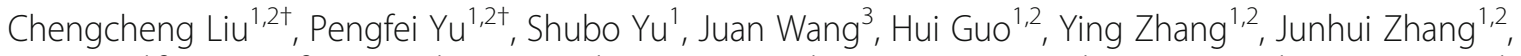
Xiyu Liao ${ }^{1,2}$, Chun Li ${ }^{2}$, Shi Wu' ${ }^{1}$, Qihui Gu', Haiyan Zeng ${ }^{1}$, Youxiong Zhang ${ }^{1}$, Xianhu Wei ${ }^{1}$, Jumei Zhang ${ }^{1}$, Qingping $\mathrm{Wu}^{1^{*}}$ and $\mathrm{Yu}$ Ding ${ }^{1,2^{*}}$ (i)

\begin{abstract}
Background: Bacillus cereus is a foodborne pathogen commonly found in nature and food and can cause food spoilage and health issues. Although the prevalence of $B$. cereus in foods has been reported worldwide, the extent of contamination in edible fungi, which has become increasingly popular as traditional or functional food, is largely unknown. Here we investigated the prevalence, toxin genes' distribution, antibiotic resistance, and genetic diversity of $B$. cereus isolated from edible fungi in China.

Results: Six hundred and ninety-nine edible fungi samples were collected across China, with 198 (28.3\%) samples found to be contaminated by $B$. cereus, with an average contamination level of 55.4 most probable number (MPN)/g. Two hundred and forty-seven B. cereus strains were isolated from the contaminated samples. Seven enterotoxin genes and one cereulide synthetase gene were detected. The detection frequencies of all enterotoxin genes were $\geq 80 \%$, whereas the positive rate of the ces $B$ gene in $B$. cereus was $3 \%$. Most isolates were resistant to penicillins, $\beta$-lactam/ $\beta$-lactamase inhibitor combinations, cephems, and ansamycins, but were susceptible to penems, aminoglycosides, macrolides, ketolide, glycopeptides, quinolones, phenylpropanol, tetracyclines, lincosamides, streptogramins, and nitrofurans. Meanwhile, $99.6 \%$ of all isolates displayed multiple antimicrobial resistance to three or more classes of antimicrobials. Using genetic diversity analysis, all isolates were defined in 171 sequence types (STs), of which 83 isolates were assigned to 78 new STs.
\end{abstract}

Conclusions: This study provides large-scale insight into the prevalence and potential risk of $B$. cereus in edible fungi in China. Approximately one-third of the samples were contaminated with B. cereus, and almost all isolates showed multiple antimicrobial resistance. Detection frequencies of all seven enterotoxin genes were equal to or more than $80 \%$. These new findings may indicate a need for proper pre-/post-processing of edible fungi to eliminate $B$. cereus, thereby preventing the potential risk to public health.

Keywords: Bacillus cereus, Edible fungi, Prevalence, Antibiotic resistance, Genetic diversity

\footnotetext{
* Correspondence: wuqp203@163.com; dingyu@jnu.edu.cn

${ }^{\dagger}$ Chengcheng Liu and Pengfei Yu contributed equally to this work.

'Guangdong Institute of Microbiology, Guangdong Academy of Science,

State Key Laboratory of Applied Microbiology Southern China, Guangdong

Provincial Key Laboratory of Microbial Safety and Health, Guangdong Open

Laboratory of Applied Microbiology, Xianlie Zhong Road 100\#, 58th Building, Guangzhou 510070, China

Full list of author information is available at the end of the article
}

(C) The Author(s). 2020 Open Access This article is licensed under a Creative Commons Attribution 4.0 International License, which permits use, sharing, adaptation, distribution and reproduction in any medium or format, as long as you give appropriate credit to the original author(s) and the source, provide a link to the Creative Commons licence, and indicate if changes were made. The images or other third party material in this article are included in the article's Creative Commons licence, unless indicated otherwise in a credit line to the material. If material is not included in the article's Creative Commons licence and your intended use is not permitted by statutory regulation or exceeds the permitted use, you will need to obtain permission directly from the copyright holder. To view a copy of this licence, visit http://creativecommons.org/licenses/by/4.0/. The Creative Commons Public Domain Dedication waiver (http://creativecommons.org/publicdomain/zero/1.0/) applies to the data made available in this article, unless otherwise stated in a credit line to the data. 


\section{Background}

Foodborne disease is an important public health issue worldwide, which is among the leading causes of morbidity and mortality [1-4]. Data from the foodborne disease outbreak surveillance and reporting system showed 5021 foodborne disease outbreaks were reported between 2001 to 2010 in China [5]. These outbreaks involved 140,101 cases and 1427 deaths, with fatality rate of $1.0 \%$, and pathogenic microorganisms accounted for most of the incidents and cases [5]. Ninety-eight foodborne disease outbreaks were reported in Shandong, China in 2014, involving 1238 patients and four deaths, mostly caused by pathogenic microorganisms [6]. The top five bacterial pathogens responsible for foodborne outbreaks from 2011 to 2016 in China were Vibrio parahaemolyticus, Salmonella spp., Staphylococcus aureus (enterotoxin), Bacillus cereus, and diarrheagenic Escherichia coli [7]. Notably, there had been 4342 foodborne cases caused by $B$. cereus during these 6 years.

$B$. cereus is a Gram-positive, spore-forming bacterium widespread in natural environment $[8,9]$. It can cause two types of food poisoning in humans, including diarrheal and emetic syndromes, along with a variety of local and systemic infections, such as endophthalmitis, endocarditis, meningitis, osteomyelitis, wound infections, and septicemia $[10,11]$. It causes diarrhea and emesis via the production of diarrheal enterotoxins and emetic toxin, respectively. The enterotoxins include hemolysin $\mathrm{BL}$ ( $\mathrm{Hbl}$ ), nonhemolytic enterotoxin (Nhe), and the singleprotein enterotoxin, cytotoxin $\mathrm{K}$ (CytK) [9, 12, 13]. Hbl and Nhe are tripartite toxins, in which all three components are necessary for maximal cytotoxic activity [14, 15]. The emetic toxin cereulide is a cyclic depsipeptide toxin encoded by the ces gene cluster [16, 17]. Emetic symptoms usually occur within $0.5-6 \mathrm{~h}$ after consuming contaminated foods [9]. Cereulide is pre-formed in food and is difficult to inactivate either during food processing or in the gastrointestinal tract, owing to its high resistance to heat treatments, extreme $\mathrm{pH}$ conditions, and enzymolysis $[9,16]$.

To date, antibiotic treatment is one choice in clinical treatment for severe food poisoning and other body or tissue infections caused by B. cereus [18-20]. However, studies have reported $B$. cereus to be resistant to different antibiotic agents, thus constituting a fundamental problem worldwide [21-23]. Information is therefore necessary for an antibiotic resistance profile of this bacterium.

$B$. cereus has been isolated from many foodstuffs, such as rice, pasta, vegetables, meat and meat products, soup, and milk and other dairy products [24-29]. However, the actual incidence rate of $B$. cereus in edible fungi remains largely unknown. From culinary perspective, edible fungi are consumed worldwide. The nutritional properties and health benefits of 'medicinal' edible fungi have been known in China for over 2000 years. Besides, edible fungi have been a part of traditional Chinese medicine, and have also been used in Japan and Malaysia [30]. B. cereus contamination could lead to spoilage of edible fungi and cause food poisoning. It is therefore necessary to investigate the prevalence of $B$. cereus in edible fungi.

The objective of this study was to investigate the contamination level and toxin gene distribution, including seven diarrheal enterotoxin genes and one emetic toxin gene across the $247 \mathrm{~B}$. cereus strains isolated from edible fungi in China. In addition, we characterized the isolates based on their antimicrobial resistance and genotypic diversity. Thereby, we provided a systematic risk assessment for B. cereus isolated from edible fungi in China.

\section{Results}

Contamination of edible fungi with $B$. cereus

The prevalence of $B$. cereus in 699 edible fungi samples examined in this study is shown in Table 1 . B. cereus was detected in $28.3 \%$ (198/699) of all samples collected and 247 isolates were isolated from these contaminated samples. Average contamination level for the positive samples was 55.4 MPN/g. 20.6\% (45/218) of Flammulina velutipes, $34.5 \%$ (39/113) of Pleurotus ostreatus, $57.8 \%$ (63/109) of Lentinus edodes, 14.7\% (14/95) of Pleurotus eryngii, $16.0 \%$ (15/94) of Hypsizygus marmoreus, and $31.4 \%(22 / 70)$ of other species were contaminated with B. cereus, respectively. The contamination levels of $81.8 \%(162 / 198)$ of positive samples ranged from 3 to $1100 \mathrm{MPN} / \mathrm{g}$, with that in five samples $(5 / 198,2.5 \%)$ exceeding $1100 \mathrm{MPN} / \mathrm{g}$.

\section{Distribution of toxin genes}

The positive rate of all seven enterotoxin genes was $\geq 80 \%$. Specifically, $80,89,91,100,90,98$, and $83 \%$ of any of the isolates harbored $h b l A, h b l C, h b l D$, nheA, $n h e B$, nhe $C$, and $c y t K$, respectively (Fig. 1; Additional file 1: Table S1). In contrast, $3 \%$ of the isolates were positive for the cereulide synthetase gene $B$ (ces $B)$. All isolates were positive for at least two toxin genes, and 157 (64\%) isolates harbored seven or more toxin genes. Among the 30 different gene profiles, the most commonly observed gene profile was $h b l A-h b l C-h b l D-n h e A-n h e B-n h e C-c y t K$, possessed by $62 \%$ of the isolates.

\section{Antibiotic susceptibility of $B$. cereus in edible fungi}

The antibiotic susceptibility results of $247 \mathrm{~B}$. cereus isolates to 20 selected antimicrobials are shown in Fig. 2. The diameters of inhibition zones in the antimicrobial susceptibility test are included in Additional file 2: Table $\mathrm{S} 2$. All isolates were resistant to ampicillin (AMP) and penicillin (P). Most isolates were resistant to amoxicillin- 
Table 1 Prevalence and contamination level of B. cereus in different edible fungi

\begin{tabular}{|c|c|c|c|c|c|}
\hline \multirow[t]{2}{*}{ Sample } & \multirow{2}{*}{$\begin{array}{l}\text { Contamination } \\
\text { rate }(\%)^{a}\end{array}$} & \multicolumn{3}{|c|}{ MPN value (MPN/g) ${ }^{b}$} & \multirow{2}{*}{$\begin{array}{l}\text { Positive } \\
\text { sample } \\
\text { contamination } \\
\text { level (MPN/g) }\end{array}$} \\
\hline & & $\mathrm{MPN}<3$ & $3 \leq \mathrm{MPN}<1100$ & $1100 \leq \mathrm{MPN}$ & \\
\hline Flammulina velutiper & $20.6(45 / 218)$ & $13 / 45(28.9 \%)$ & $31 / 45(68.9 \%)$ & $1 / 45(2.2 \%)$ & 55.5 \\
\hline Pleurotus ostreatus & $34.5(39 / 113)$ & 4/39 (10.3\%) & $33 / 39(84.6 \%)$ & $2 / 39(5.1 \%)$ & 91.7 \\
\hline Lentinus edodes & $57.8(63 / 109)$ & $5 / 63(7.9 \%)$ & $58 / 63(92.1 \%)$ & $0 / 63(0.0 \%)$ & 24.6 \\
\hline Pleurotus eryngii & $14.7(14 / 95)$ & 4/14 (28.6\%) & 10/14 (71.4\%) & 0/14 (0.0\%) & 6.8 \\
\hline Hypsizygus marmoreus & $16.0(15 / 94)$ & 2/15 (13.3\%) & 13/15 (86.7\%) & 0/15 (0.0\%) & 49.9 \\
\hline Other species & $31.4(22 / 70)$ & $3 / 22(13.6 \%)$ & 17/22 (77.3\%) & $2 / 22(9.1 \%)$ & 113.3 \\
\hline Total & $28.3(198 / 699)$ & $31 / 198(15.7 \%)$ & $162 / 198(81.8 \%)$ & $5 / 198(2.5 \%)$ & 55.4 \\
\hline
\end{tabular}

${ }^{\mathrm{a}}$ Contamination rate $=$ Number of positive samples/Total samples;

${ }^{b} \mathrm{MPN}$ value $(\mathrm{MPN} / \mathrm{g})=$ Most probable number of $B$. cereus per gram sample;

${ }^{c}$ Positive sample contamination levels (MPN/g) = Sum of MPN values for positive sample/weight of positive samples.

clavulanic acid (AMC; 99.2\%), cephalothin (KF; 85.4\%), cefoxitin (FOX; 91.9\%), and rifampin (RD; 91.1\%). Over 93\% of the isolates showed susceptibility to imipenem (IPM; 99.2\%), gentamicin (CN; 98.0\%), ciprofloxacin (CIP; 93.1\%), and chloramphenicol (C; 93.5\%). Moreover, most isolates showed intermediate resistance to clindamycin (DA; 83.8\%) and quinupristin-dalfopristin (QD; 72.1\%) (Additional file 3: Table S3).

All isolates were resistant to more than two antibiotics. Five isolates (2.0\%) were resistant to $\geq 10$ antibiotics, and 33 isolates (13.4\%) showed resistance to at least eight antibiotics (Additional file 4: Table S4). For the most common antimicrobial resistant pattern, $33.6 \%$ of the isolates harbored the profile AMP-P-AMC-KF-FOX-RD (Additional file 4: Table S4). In addition, $99.6 \%$ of all isolates displayed multiple antimicrobial resistance to three and more classes of antimicrobials (Fig. 2). Approximately 91.9 and $39.3 \%$ of the isolates showed multiple antimicrobial resistance to more than three or four classes of antimicrobials, respectively (Fig. 2).

Multi-locus sequence typing and clustering of the isolates Of the 171 STs assigned to all isolates, ST770 was the most prevalent but only included 11 isolates, and 135 STs (78.9\%) included only one isolate. Eighty-three (33.6\%) of the 247 isolates belonged to one of 78 novel STs. Of all the isolates, 141 singletons and seven clonal complexes (CCs) were assigned. The most prevalent CC was the ST-142 complex, which included 40 isolates (Additional file 4: Table S4). The ST-8, ST-18, ST-23, ST-97, ST-111, and ST-205 complexes included 3, 27, 10, 5, 2, and 19 isolates, respectively (Fig. 3; Additional file 4: Table S4). Regarding the phylogenetic relationship, all isolates were grouped into ten clusters with the cutoff value of $43 \%$ similarity (Additional file 5: Figure S1) and the cluster numbers were defined depended on the

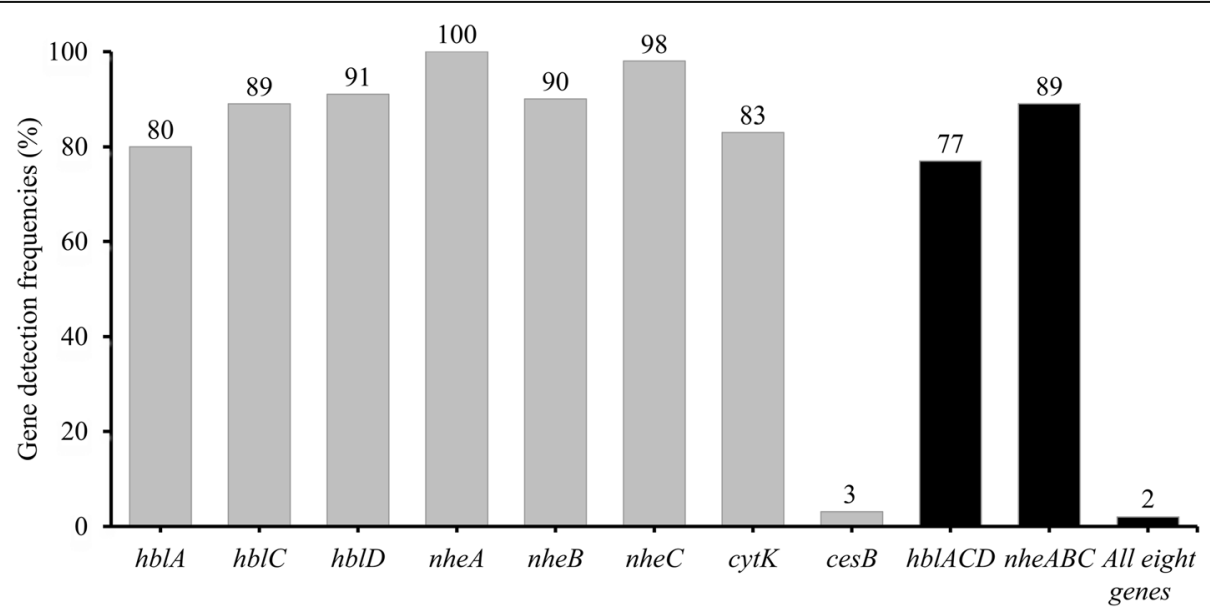

Fig. 1 Detection frequencies of toxin genes in $B$. cereus from edible fungi. The number at the top of the bars represents positive rate of corresponding toxin genes. hblACD and $n h e A B C$ show the strains to be simultaneously positive for $h b / A, h b / C$, and $h b / D ;$ or $n h e A, n h e B$, and $n h e C$, respectively. "All eight genes" represents the strains with all the detected toxin genes 


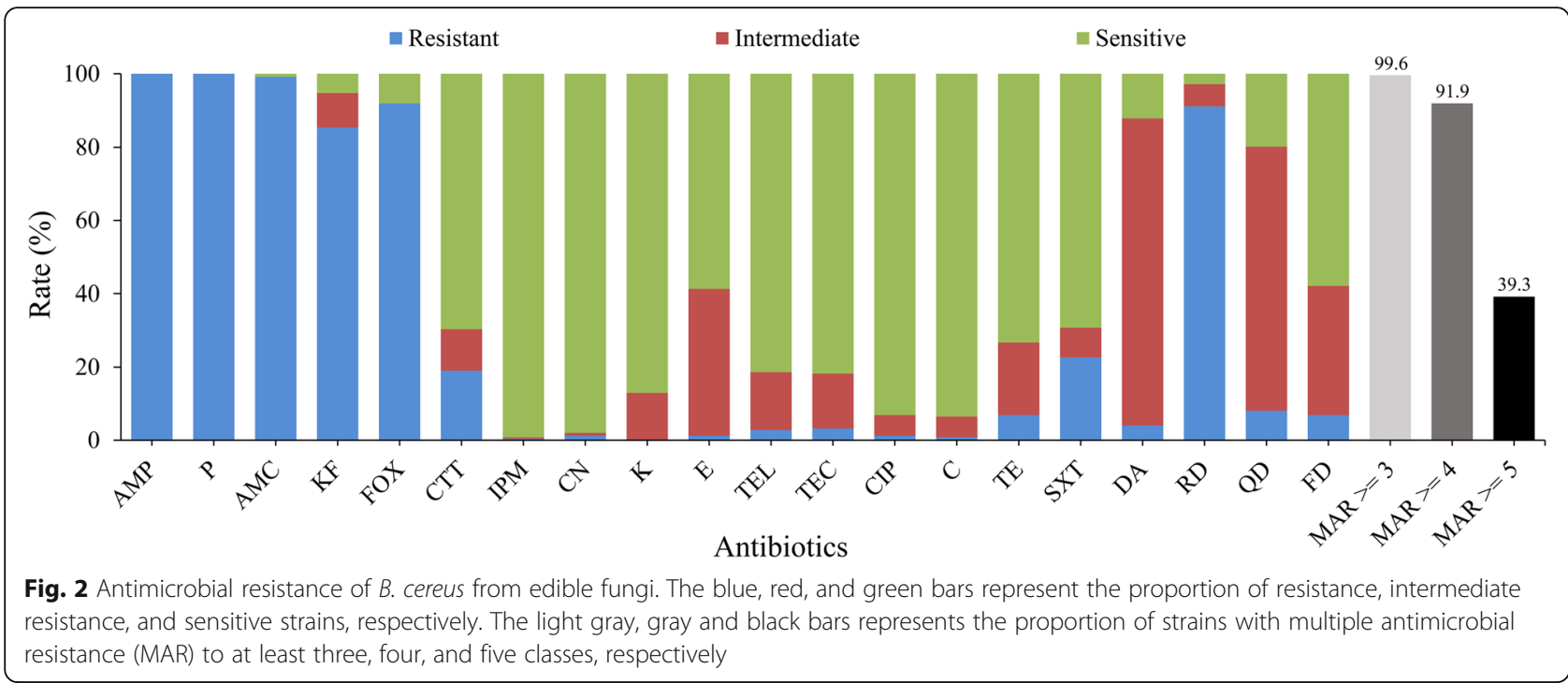

description of Guinebretière et al. [31]. Cluster III contained the most strains. Cluster IX only contained one isolate identified in this study, and cluster $\mathrm{X}$ only possessed Bacillus anthracis ATCC4728, indicating these strains were far away from the others. Isolates in cluster I were phylogenetically map together with Bacillus pseudomycoides DSM 12442, and isolates in cluster III were map together with Bacillus weihenstephanensis WSBC 10204 and Bacillus cytotoxicus NVH 391-98, which indicating that these strains may be phylogenetically close with each other.

\section{Discussion}

B. cereus is an invasive and opportunistic pathogen that can cause gastrointestinal diseases and severe nosocomial infections. To date, prevalence studies of pathogenic $B$. cereus isolated from edible fungi are limited. We therefore investigated the contamination characteristics of $B$. cereus from edible fungi collected between 2011 to 2016 . B. cereus was present in $28.3 \%$ of edible fungi samples collected from major cities of China. This suggested that more attention should be paid to the extent of contamination in edible fungi. Contamination may occur at any point during cultivation, processing, storage, and sale of the edible fungi. Compared to previous surveys with other foodstuffs $(8.2 \%$ in infant formula, $3.8 \%$ in rice flour, and $9 \%$ in ready-to-eat foods), the contamination rate of $B$. cereus isolated from edible fungi was higher [32, 33]. Unlike our previous studies which showed another important foodborne pathogen, Listeria monocytogenes, to be highly associated with $F$. velutipes $[34,35]$; here, B. cereus was frequently detected in $L$. edodes. Since $>50 \%$ of the $L$. edodes samples were positive for $B$. cereus, further studies regarding the contamination source would be recommended, considering the $B$. cereus strains to possibly be the contamination sources for the environment and other foodstuffs. In addition, the close correlation between $B$. cereus and $L$. edodes should also be investigated. Although there is no specified standard for the microbiological limits of $\mathrm{B}$. $\mathrm{Ce}$ reus in edible fungi in China, the amounts between $10^{3}$ and $10^{5} \mathrm{CFU} / \mathrm{g}$ of $B$. cereus in ready-to-eat foods are "acceptable", but not "satisfactory", according to the Microbiological Guidelines for Food of Hong Kong, China [36], hence suggesting a potential for public health risk. Studies have shown that more than $100 \mathrm{CFU} / \mathrm{g}$ of $B$. cereus in food samples may lead to foodborne infection $[37,38]$. In this study, contamination levels in $2.5 \%$ of positive samples exceeded $1100 \mathrm{MPN} / \mathrm{g}$ (Table 1). A $B$. cereus strain (strain number 49-1), isolated from one of these samples, harbored the $\operatorname{ces} B$ gene and was simultaneously identified as a ST26 strain. The reported emetic type strains F4810/72 and NC7401 [39, 40], were also identified as ST26 based on their complete genome sequences in the NCBI genome database. These results indicated a potential hazard of these contaminated edible fungi and the need for adequate cleaning and heating measures before consumption.

According to toxin gene distribution, 30 different toxin gene profiles were identified from the isolates. The detection frequency of nheABC (89\%) was similar to the findings in previous studies reporting that over $90 \%$ of isolates, from a variety of food samples, contained the nhe $A B C$ gene cluster $[28,29,41]$. Besides, the detection frequencies of $n h e C$, nheB, and nheA were close to that of $B$. cereus isolated from different food samples (100, 99, and 96\%, respectively) [38], in line with these three genes being generally prevalent in $B$. cereus isolates. The detection frequencies of $n h e A$, nheB, and $n h e C$ were not equal, which is also consistent with the previous studies 


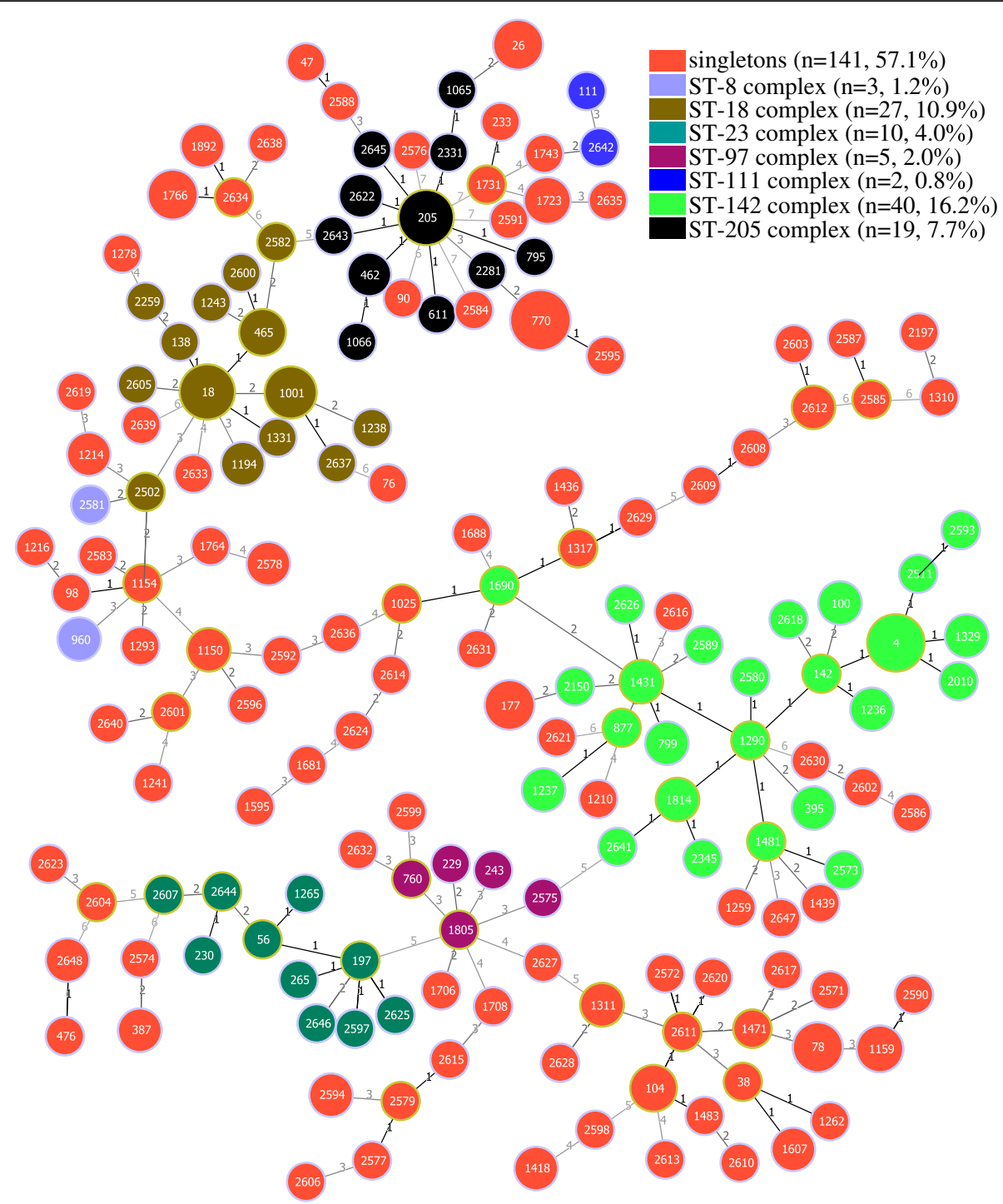

Fig. 3 Minimum spanning tree and genetic diversity of B. cereus from edible fungi. Colors inside the circles represent clonal complexes and singletons. The numbers inside the circles represent different sequence types (STs). Gradation of the line color and corresponding number along the line represent the variation of seven loci between the two strains at both ends of the line. Dominant STs are represented by circles with larger diameters

$[38,42,43]$. These three genes were not always simultaneously found in the same isolate for unknown reasons, as were the genes $h b l A, h b l C$, and $h b l D$. One possible explanation could be that the general primers used for detection cannot cover the polymorphism of target genes in different strains and affected the amplification efficiency in PCR. One hundred and ninety-one (77\%) isolates simultaneously carried the three hemolysin genes, $h b l A, h b l C$, and $h b l D$, which had higher detection frequencies than in other foodstuffs $(55 \%$ in raw milk samples, and $45 \%$ in pasteurized milk samples) [27, $28]$. The most common toxin gene profile among all isolates (62\%) was hblA-hblC-hblD-nheA-nheB-nheC-cytK, revealing that $B$. cereus isolated from edible fungi mainly harbored the diarrheal enterotoxin-encoding genes, in line with previous research [44]. Although the detection frequency of ces $B$ is lower than that of all the enterotoxin genes tested, it is still higher than that in a previous study [32], indicating the potential virulence of these isolates.

$B$. cereus has been reported to be resistant to different antimicrobials [45-47]. In this study, we found that $B$. cereus isolates from edible fungi were mainly resistant to $\beta$-lactams (except cefotetan and imipenem) and ansamycins, especially ampicillin and penicillin. Previous studies had shown that $B$. cereus harbors the antibiotic resistance genes encoding $\beta$-lactamases $[11,23,48,49]$. Therefore, $B$. cereus has the ability to degrade $\beta$-lactams and show resistant characteristics [23, 28, 29, 48, 49]. In contrast, $B$. cereus isolated from edible fungi were still 
sensitive to aminoglycosides, ketolide, glycopeptides, quinolones, and phenylpropanol antibiotics, in agreement with some previous studies [24, 27-29, 50]. Ciprofloxacin, clindamycin, and aminoglycoside antibiotics have been highly effective in the treatment of diseases caused by $B$. cereus $[11,51-53]$. However, $83.8 \%$ of the isolates in this study showed intermediate resistance to clindamycin, indicating that clindamycin may be less effective at inhibiting these isolates. Lee et al. have reported that B. cereus isolates from Sunsik were resistant to ampicillin, cefoxitin, and penicillin, which were in concordance with our results. However, their isolates were fully sensitive to chloramphenicol, gentamicin, imipenem, sulfamethoxazole, and tetracycline [54], whereas $22.7 \%$ of our isolates showed resistance to sulfamethoxazole. Luna et al. [55] and Ikram et al. [56] had reported $B$. cereus to be resistant to ampicillin, penicillin, and sensitive to chloramphenicol, ciprofloxacin, and gentamicin, similar to our findings; however, $72.1 \%$ of our isolates showed intermediate resistance to quinupristindalfopristin and $91.1 \%$ of our isolates showed resistance to rifampin. These differences may be caused by the differences in sample sources, and sampling sites. Remarkably, we found $99.6 \%$ of all the isolates to be simultaneously resistant to antibiotics from three or more antimicrobial classes, with 91.9 and $39.3 \%$ of the isolates showing multiple antimicrobial resistance to more than three or four classes, respectively. The emergence of multiple antimicrobial resistant bacteria has led to a reduction in the types and quantities of effective antibacterial drugs available for pathogen elimination, and may further lead to a decline in the effectiveness of clinical treatment for bacterial infection. The potential hazards of multiple antimicrobial resistant isolates may need further investigation.

Of the isolates studied, 33.6\% (83/247) were assigned to new STs, indicating the diverse bacterial resources not yet identified in this study. Of the 171 STs, 135 had only one isolate; thus, at least $54.7 \%$ of the isolates had a unique ST from each other, revealing the genetic diversity of isolates from edible fungi. The most prevalent ST was ST770, and the dominant CC was the ST-142 clonal complex, contradicting with previous studies [57, 58]. The reason for this phenomenon may be the difference in isolation sources of the strains. From clustering results in evolutionary analysis (Additional file 5: Figure S1), we could find specific characteristics of antibiotic resistance of the isolates. Clusters IX and X possessed only one strain each. Only isolates in cluster VI showed no QD (quinupristin-dalfopristin) resistance. Isolates in cluster I, III, IV and V showed resistance to TEL (telithromycin), and isolates in cluster III, V and VI showed resistance to TEC (teicoplanin). There were only 20, 7 , and 8 isolates showing resistance to QD, TEL, and TEC.
Three (isolates 49-1, 633-1C, and 1284) of the seven ces $B$-positive isolates identified in this study were grouped in cluster III, and they were likely to be gathered with the B. cereus emetic type strains NC7401 and F4810/72. Thus, the pathogenic potential of these strains may be higher than the others, and need to be investigated in future. Interestingly, the other four ces $B$-positive isolates were randomly distributed in different branches, suggesting the phylogenetic relationship between them to be distant, probably evolved from different origins.

\section{Conclusion}

The prevalence of $B$. cereus in about one third of the edible fungi samples in China indicated a source of potential infectious exposure to the consumers. Edible fungi samples with a B. cereus contamination level of $\geq 1100$ MPN/g suggest the importance of performing extensive cleaning and/or processing before consumption. Of the 247 isolates, 171 STs were assigned, of which 135 STs only contained one isolate and 78 new STs were defined. Moreover, $64 \%$ of the isolates harbored all the detected (seven) enterotoxins, among which four isolates further harbored the cereulide synthetase gene cesB. Three ces $B$ positive strains were identified as the same $\mathrm{ST}$ as $B$. cereus clinical emetic type strains and simultaneously phylogenetically clustered together with them. Isolates exhibiting multiple antimicrobial resistance and multiple toxin genes may indicate potential health risks related to $B$. cereus from edible fungi. Therefore, further studies would be recommended to identify the pathogenic potential of these strains.

\section{Methods}

\section{Edible fungi sample collection}

From July 2011 to January 2016, 699 edible fungi samples (including 218 Flammulina velutipes, 113 Pleurotus ostreatus, 109 Lentinus edodes, 95 Pleurotus eryngii, 94 Hypsizygus marmoreus, and 70 other species) were obtained from 39 cities, covering all the provincial capital cities of China. The details of sampling positions are shown in Additional file 6: Figure S2.

The samples were stored in sealed bags and placed in cooling boxes $\left(1-4{ }^{\circ} \mathrm{C}\right)$. They were transported to the laboratory within $12 \mathrm{~h}$ and analyzed immediately according to the general sample collection guidelines of the National Food Safety Standard [59].

\section{Identification of $B$. cereus in edible fungi}

All samples were subjected to qualitative and quantitative analysis for $B$. cereus, according to the B. cereus test standards given by the National Food Safety Standard $[60,61]$ with some modifications, as previously described [28, 29]. Twenty-five grams of the collected samples were cut and mixed with $225 \mathrm{~mL}$ phosphate buffered 
saline (PBS, $0.01 \mathrm{~mol} / \mathrm{L}$ ) under aseptic conditions. Then, 10 - and 100-fold dilutions of the homogenized solution were prepared. One milliliter of each dilution was inoculated into nine milliliters of tryptic soy broth (TSB) with polymyxin B (Huankai, Guangzhou, China) in different tubes. Each experiment was repeated in triplicate in parallel. The tubes were incubated at $30{ }^{\circ} \mathrm{C}$ for $8-18 \mathrm{~h}$. The samples were streaked onto mannitol egg yolk polymyxin (MYP) agar plates (Huankai, Guangzhou, China) and incubated at $30{ }^{\circ} \mathrm{C}$ for $24-48 \mathrm{~h}$.

The presumptive colonies, in pink color with a pink halo, were selected and streaked on the chromogenic $B$. cereus agar plates (Huankai, Guangzhou, China) and then incubated at $30{ }^{\circ} \mathrm{C}$ for $24 \mathrm{~h}$. The blue-green colonies were selected and streaked on the nutrient agar plates (Huankai, Guangzhou, China). The selected colonies were incubated and used for further analysis, including biochemical identification, parasporal crystal observation, hemolysis test, MYP agar plate test, root growth observation, catalase test, motility test, nitrate reduction test, casein decomposition test, lysozyme tolerance test, glucose utilization test, and acetyl methyl alcohol test, described in the National Food Safety Standard [60, 61] and the Bacteriological Nnalytical Manuals of the U.S. Food and Drug Administration [62]. The isolate, which 1) produces large Gram-positive rods with spores that does not swell the sporangium; 2) produces lecithinase and does not ferment mannitol on MYP agar; 3) grows and produces acid from glucose anaerobically; 4) reduces nitrate to nitrite (a few strains may be negative); 5) produces acetylmethylcarbinol (VP-positive); 6) decomposes L-tyrosine; 7) grows in the presence of $0.001 \%$ lysozyme; 8 ) is actively motile and strongly hemolytic; 9) does not produce rhizoid colonies or protein toxin crystals, can be identified as $B$. cereus. The most probable number (MPN), which represents the number of corresponding bacteria most likely to be present per gram of sample, of $B$. cereus for the samples was determined according to the National Food Safety Standard [60, 61], the Bacteriological Nnalytical Manuals of the U.S. Food and Drug Administration [62], and previous studies [29, 63, 64].

\section{Detection of toxin genes}

Genomic DNA was extracted from B. cereus using a HiPure DNA Extraction Kit (Magen, Guangzhou, China), according to the manufacturer's instructions. Eight toxin genes, including seven enterotoxin genes (nheA, nheB, nheC, hblC, hblD, hblA, and cytK) and a cereulide synthetase gene $B(\operatorname{ces} B)$ were detected. The primers used for the detection of toxin genes and their annealing temperature are shown in Additional file 7: Table S5.

The polymerase chain reaction (PCR) mixture $(25 \mu \mathrm{L})$ comprised of $50 \mathrm{ng}$ genomic DNA, $0.5 \mu \mathrm{L}$ of each primer solution (concentration $10 \mu \mathrm{M}$ ), and $12.5 \mu \mathrm{L}$ PCR Premix $\mathrm{Taq}^{\mathrm{TM}}$ (Takara, China). The amplification process included: initial denaturation at $94{ }^{\circ} \mathrm{C}$ for $5 \mathrm{~min}, 30$ cycles of $94{ }^{\circ} \mathrm{C}$ for $1 \mathrm{~min}, 55^{\circ} \mathrm{C}$ or $58{ }^{\circ} \mathrm{C}\left(58^{\circ} \mathrm{C}\right.$ for cesB and $55^{\circ} \mathrm{C}$ for the other toxin genes) for $1 \mathrm{~min}, 72^{\circ} \mathrm{C}$ for 1 min, and a final $10 \mathrm{~min}$ extension at $72^{\circ} \mathrm{C}[17,43,65$, 66]. PCR was conducted in a TONE-96G PCR Thermal Cycler (Analytik Jena, Jena, Germany). Amplicons were subjected to electrophoresis using 1.5\% agarose gel containing $0.01 \%$ Gold View. The gels were visualized by a UV Imaging System (Bio-Rad, Hercules, USA). A 2000bp DNA ladder (Dongsheng, Guangzhou, China) was used as a molecular weight marker. The images were captured in TIFF file format for further analysis.

\section{Antimicrobial susceptibility test}

Antimicrobial susceptibility was evaluated using the Kirby-Bauer disk diffusion method on Mueller-Hinton $(\mathrm{MH})$ agar for 20 selected antimicrobial drugs belonging to 16 different classes [28, 29,67]. The details of antimicrobial agents (Oxoid, Basingstoke, UK) are shown in Fig. 2, and Additional file 3: Table S3. Following the methods of CLSI [67] and previous research [23, 68-71], results were expressed as resistant (R), intermediate (I), and sensitive $(\mathrm{S})$. The zone diameter interpretive criteria are shown in Additional file 8: Table S6, with reference to CLSI [66]. In addition, multiple antimicrobial resistant isolates, showing resistance to antibiotics from three or more antimicrobial classes, were also evaluated.

\section{Multi-locus sequence typing and clustering of different isolates}

Seven housekeeping genes ( $g l p, g m k$, ilvD, pta, pur, $p y c A$, and $t p i$ ) were amplified, sequenced, and analyzed to obtain the multi-locus sequence type of the isolates according to the MLST scheme which was developed by Martin Maiden, Gus Priest, and Maggie Barker [72] on the PubMLST official website (http://pubmlst.org/bcereus/info/primers.shtml). PHYLOViZ 2.0 software (Instituto de Microbiologia, Portugal) was used to construct a minimum spanning tree of the isolates [73], to visualize the genetic diversity and inter-strain relationships. The phylogenetic relationship between different isolates was studied depending on the different STs and seven housekeeping genes, using the BioNumerics software (version 7.6; Applied Maths, Belgium) with the arithmetic mean (UPGMA) method. The strains used in the phylogenetic study contained 247 isolates identified in this study, and nine isolates (B. cereus ATCC14579, Bacillus mycoides DSM 2048, Bacillus pseudomycoides DSM 12442, Bacillus weihenstephanensis WSBC 10204, Bacillus anthracis ATCC4728, Bacillus thuringiensis ATCC10792, Bacillus cytotoxicus NVH 391-98 and two clinical emetic type strains B. cereus NC7401 and B. cereus F4810/72) from 
the B. cereus MLST database (www.mlstoslo.uio.no/ index.html) or NCBI genome database (https://www. ncbi.nlm.nih.gov/genome/). The names of isolates, MLST sequence type (ST), MLST clonal complex (CC), antibiotic resistance patterns, and presence of toxin genes were also included.

\section{Supplementary information}

Supplementary information accompanies this paper at https://doi.org/10. 1186/s12866-020-01996-0.

Additional file 1: Table S1. Prevalence of toxin genes in B. cereus isolated from edible fungi in China.

Additional file 2: Table S2. The diameters of inhibition zones in antimicrobial susceptibility test. Among the zone diameter interpretive criteria for the antimicrobials used, the minimum value for the antimicrobial resistance interpretive criteria is $10 \mathrm{~mm}$. When there is no bacteriostatic zone or the bacteriostatic zone diameter is less than $8 \mathrm{~mm}$, the results are directly recorded as " $\mathrm{R}$ ".

Additional file 3: Table S3. Results of antibiotic resistance test for $B$. cereus isolates in the study.

Additional file 4: Table S4. The MLST typing results, and the profiles of antibiotic resistance and toxin genes of all isolates. "**" represents a new ST.

Additional file 5: Figure S1. Phylogenetic analysis of 247 B. cereus isolates from edible fungi and eight type strains based on the MLST typing results. A cut-off value of $43 \%$ similarity was applied to define the clusters. ATCC14579: B. cereus ATCC14579; DSM 2048: Bacillus mycoides DSM 2048; DSM 12442: Bacillus pseudomycoides DSM 12442; WSBC 10204: Bacillus weihenstephanensis WSBC 10204; ATCC4728: Bacillus anthracis ATCC4728; ATCC10792: Bacillus thuringiensis ATCC10792; NVH 391-98: Bacillus cytotoxicus NVH 391-98; NC7401: clinical emetic type strain B. cereus NC7401; F4810/72: clinical emetic type strain B. cereus F4810/72.

Additional file 6: Figure S2. Sampling cities where the edible fungi were collected. Sampling plan design and this sampling map were all done by ourselves.

Additional file 7: Table S5. Primers used in this study.

Additional file 8: Table S6. Zone diameter interpretive criteria for the antimicrobials used in this study.

\section{Abbreviations}

MPN: Most probable number; Hbl: Hemolysin BL; Nhe: Nonhemolytic enterotoxin; CytK: Cytotoxin K; cesB: Cereulide synthetase gene $B$; AMP: Ampicillin; P: Penicillin; AMC: Amoxicillin-clavulanic acid; KF: Cephalothin; FOX: Cefoxitin; RD: Rifampin; IPM: Imipenem; CN: Gentamicin; CIP: Ciprofloxacin; C: Chloramphenicol; DA: Clindamycin; QD: Quinupristin-dalfopristin; FD: Nitrofurantoin; MLST: Multi-locus sequence typing; CCs: Clonal complexes; CFU: Colony-forming unit; PBS: Phosphate buffered saline; TSB: Tryptic soy broth; MYP: Mannitol egg yolk polymyxin; PCR: Polymerase chain reaction; MH: Mueller-hinton; R: Resistant; I: Intermediate; S: Sensitive; MAR: Multiple antimicrobial resistance

\section{Acknowledgements}

The authors would like to thank the mlstoslo web database (www.mlstoslo. uio.no/) for the assistance of B. cereus MLST information of different strains.

\section{Authors' contributions}

YD, QPW, JW, JMZ, CCL and PFY conceived the project and designed the experiments; CCL, PFY, SBY, HG, YZ, JHZ, XYL, CL, SW, QHG, HYZ, YXZ, and $X H W$ performed the experiments; $Y D$ and QPW supervised the project; $C C L$, PFY and YD analyzed the data and wrote the article; QPW, JW and YD complemented the writing. All authors have read and approved the manuscript.

\section{Funding}

The present work was financially supported by the Guangdong Technological Innovation Strategy of Special Funds (Key-Area of Research and Development Program of Guangdong Province, grant number 2018B020205003), National Key R\&D Program of China (grant number 2018YFC1602500), National Natural Science Foundation of China (grant numbers 31730070 and 31701195), Science and Technology Program of Guangdong Province (grant number 2017A070702018), GDAS' Special Project of Science and Technology Development (grant number 2017GDASCX-0201), and the 1000-Youth Elite Program and the 111 Project. The funding bodies were not involved in the design of the study and collection, analysis, interpretation of data, and writing of the manuscript.

\section{Availability of data and materials}

Genetic polymorphisms data used for Additional file 5: Figure S1 has been list in Additional file 4: Table S4. The sequence type and corresponding DNA sequences of seven housekeeping genes ( $g$ lp, gmk, ilvD, pta, pur, pycA, and tpi) were all available and can be downloaded from the public MLST database (https://pubmlst.org/bcereus/) according to the STs of the isolates list in Additional file 4: Table S4. All other data generated or analyzed during this study are included in this manuscript and its supplementary information files.

Ethics approval and consent to participate

Not applicable.

\section{Consent for publication}

Not applicable.

\section{Competing interests}

The authors declare that they have no competing interests.

\section{Author details}

${ }^{1}$ Guangdong Institute of Microbiology, Guangdong Academy of Science, State Key Laboratory of Applied Microbiology Southern China, Guangdong Provincial Key Laboratory of Microbial Safety and Health, Guangdong Open Laboratory of Applied Microbiology, Xianlie Zhong Road 100\#, 58th Building, Guangzhou 510070, China. ${ }^{2}$ Department of Food Science and Technology, Institute of Food Safety and Nutrition, Jinan University, Huangpu Ave. 601, Guangzhou 510632, China. ${ }^{3}$ College of Food Science, South China Agricultural University, Guangzhou, China.

Received: 16 January 2020 Accepted: 5 October 2020

Published online: 14 October 2020

\section{References}

1. Wu G, Yuan Q, Wang L, Zhao J, Chu Z, Zhuang M, Zhang Y, Wang K, Xiao P, Liu $Y$, et al. Epidemiology of foodborne disease outbreaks from 2011 to 2016 in Shandong Province, China. Medicine (Baltimore). 2018;97(45): e13142.

2. Jahan S. Epidemiology of Foodborne IIIness. In., vol. 336; 2012.

3. Helms M, Vastrup P, Gerner-Smidt P, Mølbak K. Short and long term mortality associated with foodborne bacterial gastrointestinal infections: registry based study. BMJ. 2003;326(7385):357.

4. Alcorn T, Ouyang Y. China's invisible burden of foodborne illness. Lancet. 2012;379(9818):789-90.

5. Xu J, Zhang J. Analysis of foodborne disease outbreaks in China from 2001 to 2010. Chin Agri Sci Bull. 2012;28:313-6 (in Chinese).

6. Zong JW, Zhou JY, Zhao JS, Chu ZH, Wang LS, Yan JY. Monitoring data of foodborne disease outbreaks in Shandong Province, 2014. Pract Prev Med. 2018;1 (25):122-5 (in Chinese).

7. Liu J, Bai L, Li W, Han H, Fu P, Ma X, Bi Z, Yang X, Zhang X, Zhen S, et al. Trends of foodborne diseases in China: lessons from laboratory-based surveillance since 2011. Front Med. 2018;12(1):48-57.

8. European Food Safety Authority (EFSA). Opinion of the scientific panel on biological hazards on Bacillus cereus and other Bacillus spp. in foodstuffs. EFSA J. 2005;175:1-48. https://doi.org/10.2903/j.efsa.2005.175.

9. Stenfors Arnesen LP, Fagerlund A, Granum PE. From soil to gut: Bacillus cereus and its food poisoning toxins. FEMS Microbiol Rev. 2008;32(4):579-606.

10. Drobniewski FA. Bacillus cereus and related spcies. Clin Microbiol Rev. 1993; 6(4):324-38. 
11. Bottone EJ. Bacillus cereus, a volatile human pathogen. Clin Microbiol Rev. 2010;23(2):382-98.

12. Lund T, De Buyser ML, Granum PE. A new cytotoxin from Bacillus cereus that may cause necrotic enteritis. Mol Microbiol. 2000;38(2):254-61.

13. Ehling-Schulz $M$, Guinebretière $M H$, Monthán $A$, Berge $O$, Fricker $M$, Svensson B. Toxin gene profiling of enterotoxic and emetic Bacillus cereus. FEMS Microbiol Lett. 2006;260(2):232-40.

14. Beecher DJ, Macmillan JD. Characterization of the components of hemolysin BL from Bacillus cereus. Infect Immun. 1991;59(5):1778-84

15. Lindbäck T, Fagerlund A, Rødland MS, Granum PE. Characterization of the Bacillus cereus Nhe enterotoxin. Microbiology. 2004;150(Pt 12):3959-67.

16. Agata N, Ohta M, Mori M, Isobe M. A novel dodecadepsipeptide, cereulide, is an emetic toxin of Bacillus cereus. FEMS Microbiol Lett. 1995;129(1):17-20.

17. Ehling-Schulz M, Vukov N, Schulz A, Shaheen R, Andersson M, Märtlbauer E, Scherer S. Identification and partial characterization of the nonribosomal peptide synthetase gene responsible for cereulide production in emetic Bacillus cereus. Appl Environ Microbiol. 2005;71(1):105-13.

18. Kervick GN, Flynn HW Jr, Alfonso E, Miller D. Antibiotic therapy for Bacillus species infections. Am J Ophthalmol. 1990;110(6):683-7.

19. Dierick K, Van Coillie E, Swiecicka I, Meyfroidt G, Devlieger H, Meulemans A, Hoedemaekers G, Fourie L, Heyndrickx M, Mahillon J. Fatal family outbreak of Bacillus cereus-associated food poisoning. J Clin Microbiol. 2005;43(8): 4277-9.

20. Veysseyre F, Fourcade C, Lavigne JP, Sotto A. Bacillus cereus infection: 57 case patients and a literature review. Med Mal Infect. 2015;45(11-12):436-40.

21. Agers $\varnothing$ Y, Jensen LB, Givskov M, Roberts MC. The identification of a tetracycline resistance gene tet( $M$ ), on a Tn916-like transposon, in the Bacillus cereus group. FEMS Microbiol Lett. 2002;214(2):251-6.

22. Brown JR, Gentry D, Becker JA, Ingraham K, Holmes DJ, Stanhope MJ. Horizontal transfer of drug-resistant aminoacyl-transfer-RNA synthetases of anthrax and gram-positive pathogens. EMBO Rep. 2003;4(7):692-8.

23. Torkar KG, Bedenić B. Antimicrobial susceptibility and characterization of metallo-beta-lactamases, extended-spectrum beta-lactamases, and carbapenemases of Bacillus cereus isolates. Microb Pathog. 2018;118:140-5.

24. Wijnands LM, Dufrenne JB, Rombouts FM, In't Veld PH, Van Leusden FM. Prevalence of potentially pathogenic Bacillus cereus in food commodities in The Netherlands. J Food Prot. 2006;69(11):2587-94.

25. Chaves JQ, Pires ES, Vivoni AM. Genetic diversity, antimicrobial resistance and toxigenic profiles of Bacillus cereus isolated from food in Brazil over three decades. Int J Food Microbiol. 2011;147(1):12-6.

26. Chon JW, Yim JH, Kim HS, Kim DH, Kim H, Oh DH, Kim SK, Seo KH. Quantitative prevalence and toxin gene profile of Bacillus cereus from readyto-eat vegetables in South Korea. Foodborne Pathog Dis. 2015;12(9):795-9.

27. Cui Y, Liu X, Dietrich R, Märtlbauer E, Cao J, Ding S, Zhu K. Characterization of Bacillus cereus isolates from local dairy farms in China. FEMS Microbiol. Lett. 2016;363(12):fnw096.

28. Gao T, Ding Y, Wu Q, Wang J, Zhang J, Yu S, Yu P, Liu C, Kong L, Feng Z. Prevalence, virulence genes, antimicrobial susceptibility, and genetic diversity of Bacillus cereus isolated from pasteurized milk in China. Front Microbiol. 2018;9:533.

29. Yu P, Yu S, Wang J, Guo H, Zhang Y, Liao X, Zhang J, Wu S, Gu Q, Xue L, et al. Bacillus cereus isolated from vegetables in China: incidence, genetic diversity, virulence genes, and antimicrobial resistance. Front Microbiol. 2019;10:948

30. Sadler M. Nutritional properties of edible fungi. Nutr Bull. 2003:28(3):305-8.

31. Guinebretière $M H$, Thompson FL, Sorokin A, Normand P, Dawyndt $P$, EhlingSchulz M, Svensson B, Sanchis V, Nguyen-The C, Heyndrickx M, et al. Ecological diversification in the Bacillus cereus group. Environ Microbiol. 2008;10(4):851-65.

32. Zhang Y, Chen J, Feng C, Zhan L, Zhang J, Li Y, Yang Y, Chen H, Zhang Z, Zhang $Y$, et al. Quantitative prevalence, phenotypic and genotypic characteristics of Bacillus cereus isolated from retail infant foods in China. Foodborne Pathog Dis. 2017;14(10):564-72.

33. Forero AY, Galindo M, Morales GE. Isolation of Bacillus cereus in school restaurants in Colombia. Biomedica. 2018;38(3):338-44.

34. Chen M, Wu Q, Zhang J, Guo W, Wu S, Yang X. Prevalence and contamination patterns of Listeria monocytogenes in Flammulina velutipes plants. Foodborne Pathog Dis. 2014;11(8):620-7.

35. Wu S, Wu Q, Zhang J, Chen M, Yan ZA, Hu H. Listeria monocytogenes prevalence and characteristics in retail raw foods in China. PLoS One. 2015 10(8):e0136682.
36. Food and environmental hygiene department. Microbiological Guidelines for Food. Hong Kong: Food and environmental hygiene department. 2014.

37. Ghelardi E, Celandroni F, Salvetti S, Barsotti C, Baggiani A, Senesi S. Identification and characterization of toxigenic Bacillus cereus isolates responsible for two food-poisoning outbreaks. FEMS Microbiol Lett. 2002; 208(1):129-34

38. Glasset B, Herbin S, Guillier L, Cadel-Six S, Vignaud ML, Grout J, Pairaud S, Michel V, Hennekinne JA, Ramarao N, et al. Bacillus cereus-induced foodborne outbreaks in France, 2007 to 2014: epidemiology and genetic characterisation. Euro Surveill. 2016;21(48):30413.

39. Häggblom MM, Apetroaie C, Andersson MA, Salkinoja-Salonen MS. Quantitative analysis of cereulide, the emetic toxin of Bacillus cereus, produced under various conditions. Appl Environ Microbiol. 2002;68(5): 2479-83.

40. Takeno A, Okamoto A, Tori K, Oshima K, Hirakawa H, Toh H, Agata N, Yamada K, Ogasawara N, Hayashi T, et al. Complete genome sequence of Bacillus cereus NC7401, which produces high levels of the emetic toxin cereulide. J Bacteriol. 2012;194(17):4767-8.

41. Kim JB, Kim JM, Cho SH, Oh HS, Choi NJ, Oh DH. Toxin genes profiles and toxin production ability of Bacillus cereus isolated from clinical and food samples. J Food Sci. 2011;76(1):T25-9.

42. Carter L, Chase HR, Gieseker CM, Hasbrouck NR, Stine CB, Khan A, EwingPeeples $L$, Tall BD, Gopinath GR. Analysis of enterotoxigenic Bacillus cereus strains from dried foods using whole genome sequencing, multi-locus sequence analysis and toxin gene prevalence and distribution using endpoint PCR analysis. Int J Food Microbiol. 2018;284:31-9.

43. Hansen BM, Hendriksen NB. Detection of enterotoxic Bacillus cereus and Bacillus thuringiensis strains by PCR analysis. Appl Environ Microbiol. 2001; 67(1):185-9.

44. Saleh-Lakha S, Leon-Velarde CG, Chen S, Lee S, Shannon K, Fabri M, Downing G, Keown B. A study to assess the numbers and prevalence of Bacillus cereus and its toxins in pasteurized fluid milk. J Food Prot. 2017; 80(7):1085-9.

45. Barbosa TM, Levy SB. The impact of antibiotic use on resistance development and persistence. Drug Resist Updat. 2000;3(5):303-11.

46. Savić D, Miljković-Selimović B, Lepšanović Z, Tambur Z, Konstantinović S, Stanković N, Ristanović E. Antimicrobial susceptibility and beta-lactamase production in Bacillus cereus isolates from stool of patients, food and environment samples. Vojnosanit Pregl. 2016;73(10):904-9.

47. Shawish $R$, Tarabees R. Prevalence and antimicrobial resistance of Bacillus cereus isolated from beef products in Egypt. Open Vet J. 2017;7(4):337-41.

48. Madonna MJ, Zhu YF, Lampen JO. Nucleotide sequence of the betalactamase I gene of Bacillus cereus strains 569/H and 5/B. Nucleic Acids Res. 1987;15(4):1877.

49. Hussain M, Pastor Fl, Lampen JO. Cloning and sequencing of the blaZ gene encoding beta-lactamase III, a lipoprotein of Bacillus cereus 569/H. J Bacteriol. 1987;169(2):579-86.

50. Park YB, Kim JB, Shin SW, Kim JC, Cho SH, Lee BK, Ahn J, Kim JM, Oh DH. Prevalence, genetic diversity, and antibiotic susceptibility of Bacillus cereus strains isolated from rice and cereals collected in Korea. J Food Prot. 2009; 72(3):612-7.

51. Gascoigne AD, Richards J, Gould K, Gibson GJ. Successful treatment of Bacillus cereus infection with ciprofloxacin. Thorax. 1991;46(3):220-1.

52. Kemmerly SA, Pankey GA. Oral ciprofloxacin therapy for Bacillus cereus wound infection and bacteremia. Clin Infect Dis. 1993;16(1):189.

53. Katsuya H, Takata T, Ishikawa T, Sasaki H, Ishitsuka K, Takamatsu Y, Tamura K. A patient with acute myeloid leukemia who developed fatal pneumonia caused by carbapenem-resistant Bacillus cereus. J Infect Chemother. 2009; 15(1):39-41.

54. Lee N, Sun JM, Kwon KY, Kim HJ, Koo M, Chun HS. Genetic diversity, antimicrobial resistance, and toxigenic profiles of Bacillus cereus strains isolated from Sunsik. J Food Prot. 2012;75(2):225-30.

55. Luna VA, King DS, Gulledge J, Cannons AC, Amuso PT, Cattani J. Susceptibility of Bacillus anthracis, Bacillus cereus, Bacillus mycoides, Bacillus pseudomycoides and Bacillus thuringiensis to 24 antimicrobials using Sensititre automated microbroth dilution and Etest agar gradient diffusion methods. J Antimicrob Chemother. 2007:60(3):555-67.

56. Ikram S, Heikal A, Finke S, Hofgaard A, Rehman Y, Sabri AN, Økstad OA. Bacillus cereus biofilm formation on central venous catheters of hospitalised cardiac patients. Biofouling. 2019;35(2):204-16. 
57. Liu Y, Lai Q, Du J, Shao Z. Genetic diversity and population structure of the Bacillus cereus group bacteria from diverse marine environments. Sci Rep. 2017;7(1):689.

58. Yang $Y, Y u X$, Zhan L, Chen J, Zhang Y, Zhang J, Chen H, Zhang Z, Zhang Y, Lu Y, et al. Multilocus sequence type profiles of Bacillus cereus isolates from infant formula in China. Food Microbiol. 2017;62:46-50.

59. The Hygiene Ministry of China. National food safety standard. Food microbiological examination: General guidelines. Beijing: The Hygiene Ministry of China; 2010

60. The Hygiene Ministry of China. National food safety standard. Food microbiological examination: Bacillus cereus test. Beijing: The Hygiene Ministry of China. 2003.

61. The Hygiene Ministry of China. National food safety standard. Food microbiological examination: Bacillus cereus test. Beijing: The Hygiene Ministry of China; 2014

62. Tallent, S. M., Rhodehamel, E. J., Harmon, S. M., and Bennett, R. W. (2012). Bacteriological analytical manual; methods for specific pathogens. U. S. Food and Drug Administration. Chapter 14, Bacillus cereus (updated November 2019). 2012. Available at: https://www.fda.gov/food/laboratorymethods-food/bam-bacillus-cereus. Accessed 16 April, 2020.

63. Hariram U, Labbé R. Spore prevalence and toxigenicity of Bacillus cereus and Bacillus thuringiensis isolates from U.S. retail spices. J. Food Prot. 2015;78(3): 590-6.

64. Harper NM, Getty KJ, Schmidt KA, Nutsch AL, Linton RH. Comparing the mannitol-egg yolk-polymyxin agar plating method with the three-tube most-probable-number method for enumeration of Bacillus cereus spores in raw and high-temperature, short-time pasteurized milk. J Food Prot. 2011; 74(3):461-4.

65. Fagerlund A, Ween O, Lund T, Hardy SP, Granum PE. Genetic and functional analysis of the cytK family of genes in Bacillus cereus. Microbiology. 2004;150: 2689-97.

66. Oltuszak-Walczak E, Walczak P. PCR detection of cytK gene in Bacillus cereus group strains isolated from food samples. J Microbiol Methods. 2013;95(2): 295-301.

67. The Clinical. And laboratory standards institute (CLSI). Performance standards for antimicrobial susceptibility testing; twentieth informational supplement. Approved standard-M100-S20. Wayne, PA: The Clinical and Laboratory Standards Institute; 2010.

68. Mohammed MJ, Marston CK, Popovic T, Weyant RS, Tenover FC Antimicrobial susceptibility testing of Bacillus anthracis: comparison of results obtained by using the National Committee for clinical laboratory standards broth microdilution reference and Etest agar. Gradient diffusion methods. J Clin Microbiol. 2002;40(6):1902-7.

69. Osman KM, Kappell AD, Orabi A, Al-Maary KS, Mubarak AS, Dawoud TM, Hemeg HA, Moussa IMI, Hessain AM, Yousef HMY, et al. Poultry and beef meat as potential seedbeds for antimicrobial resistant enterotoxigenic Bacillus species: a materializing epidemiological and potential severe health hazard. Sci Rep. 2018:8(1):11600.

70. Park KM, Jeong M, Park KJ, Koo M. Prevalence, enterotoxin genes, and antibiotic resistance of Bacillus cereus isolated from raw vegetables in Korea. J Food Prot. 2018;81(10):1590-7.

71. Yusuf U, Kotwal SK, Gupta S, Ahmed T. Identification and antibiogram pattern of Bacillus cereus from the milk and milk products in and around Jammu region. Vet World. 2018;11(2):186-91.

72. Jolley KA, Bray JE, Maiden MCJ. Open-access bacterial population genomics: BIGSdb software, the PubMLST.org website and their applications. Wellcome Open Res. 2018; 3:124

73. Ribeiro-Gonçalves B, Francisco AP, Vaz C, Ramirez M, Carriço JA. PHYLOViZ online: web-based tool for visualization, phylogenetic inference, analysis and sharing of minimum spanning trees. Nucleic Acids Res. 2016;44(W1): W246-51.

\section{Publisher's Note}

Springer Nature remains neutral with regard to jurisdictional claims in published maps and institutional affiliations.

\section{Ready to submit your research? Choose BMC and benefit from:}

- fast, convenient online submission

- thorough peer review by experienced researchers in your field

- rapid publication on acceptance

- support for research data, including large and complex data types

- gold Open Access which fosters wider collaboration and increased citations

- maximum visibility for your research: over $100 \mathrm{M}$ website views per year

At BMC, research is always in progress.

Learn more biomedcentral.com/submissions 